\title{
November 2015
}

True $(A)$ of false $(B)$

The 2015 Sexual Offences Amendment Act: Laudable amendment in line with the Teddy Bear clinic case:

1. Adolescents engaging in sexual activity with other adolescents will be prosecuted in line with current law.

2 The age of sexual consent is 16 years and has not been lowered to 12 years.

3. A 17-year-old who has consensual sex with a 13-year-old and impregnates her commits an offence because there is more than two years age gap between these parties.

Ethical guidelines for military-based health research: An unmet need in Africa:

4. The military is avoided as a site for research.

5. Military health personnel and soldiers work in complex cultural environments that often contrast with civilian life.

6. Decisions and orders from superior members of the armed forces could be applied to the entire troop easily because of the strong notion of respect for hierarchy and orders.

\section{Moral challenges in managed care:}

7. Managed healthcare is defined in Regulation 15 of the Managed Health Care Act.

8. In Beauchamp and Childress's four main biomedical ethics principles, respect for autonomy has prima facie value over the other three principles.

The mandatory reporting of consensual, underage sex: Knowledge, practices and perspectives of social workers in KwaZulu-Natal:

9. Recent research in South Africa has found that many young adolescents do not engage in a variety of sexual behaviours.

10. The Sexual Offences Amendment Act (No 5 of 2015), was signed into law in July 2015.

Public health, beneficence and cosmopolitan justice:

11. The recent Ebola epidemic highlights the fact that countries with under-developed health systems and limited resources cannot cope with a significant and sudden health threat.
12. Globalised world economies are not inter-linked and interdependent on each other.

\section{Public health and social justice: Forging the links:}

13. The generally accepted definition of public health is an approach to health that is concerned primarily with the health of communities or populations and delivered primarily by organisations or government rather than individuals.

14. The burden of disease and life expectancy is inextricably linked to poverty and persistent patterns of discrimination, most notably against women.

Stransham-Ford v. Minister of Justice and Correctional Services and Others: Can active voluntary euthanasia and doctor-assisted suicide be legally justified and are they consistent with the biomedical ethical principles? Some suggested guidelines for doctors to consider:

15. The Stransham-Ford case was a judgment by a single high court judge and the decision is binding on all courts in the country.

16. In law intention may be 'actual' or 'eventual'.

\section{Virtue ethics: Beyond moral theory:}

17. Many moral problems in medicine involve tensions between conflicting moral obligations.

18. Virtue ethics suggests that the physician is simply an inanimate observer in the process of ethical deliberation.

Nanotechnology in medicine and healthcare: Possibilities, progress and problems:

19. Nanotechnology has the power to revolutionise the practice of medicine and the delivery and accessibility of healthcare.

20. If nanotechnology does not seek to benefit wider society by responding to social needs it could widen the gap between rich and poor.

A maximum of 6 CEUs will be awarded per correctly completed test.

The CPD programme for SAJBL will be administered by Medical Practice Consulting:

CPD questionnaires must be completed online at www.mpconsulting.co.za

After submission you can check the answers and print your certificate.

Questions may be answered up to 6 months after publication of each issue.

Accreditation number: MDB015/164/02/2015 (Ethics) 